\title{
Monitoring of Anthracene Using Nanoscale Au-Cu Bimetallic Alloy Nanoparticles Synthesized with Various Composition
}

Latif-ur-Rahman ${ }^{*}$, , Afzal Shah $¥$, Changseok Han ${ }^{\S}$, Abdul Khaliq Jan ${ }^{\#}$

†Institute of Chemical Sciences University of Peshawar 25120, Pakistan

†Department of Chemistry Quaid-i-Azam University, Islamabad, 45320, Pakistan

$\$$ Department of Chemistry, College of Science, University of Bahrain, Sakhir, 32038, The Kingdom of Bahrain

$\S$ Department of Environmental Engineering, INHA University, Incheon, Korea

\#Department of Chemistry, Shaheed Benazir Bhutto University, Dir, Pakistan

*To whom correspondence should be addressed

E-mails: latif.wardag@uop.edu.pk and latif.wardag@gmail.com(Dr. Latif-ur-Rahman) 


\section{Supporting Information}

Figure $\mathrm{S} 1$ shows XRD patterns of $\mathrm{Au}-\mathrm{Cu}$ alloy nanoparticles prepared by polyols process. The distinct signals are observed at $42^{\circ}, 58^{\circ}$ and $95^{\circ}$ corresponding to 111,200 and 210 of $\mathrm{Au}-\mathrm{Cu}(3: 1)$ NPs. Similarly, Figure S2 reflects XRD pattern (observed at $40^{\circ}, 55^{\circ}$ and $90^{\circ}$ corresponding to 111,200 and 210) of $\mathrm{Au}-\mathrm{Cu}(1: 1)$ alloy NPs synthesized by the polyol process from $\mathrm{AuCl}_{3}, \mathrm{CuCl}_{2}$ in the presence of PVP as a capping agent. Figure $\mathrm{S} 3$ is an Equivalent Circuit model.

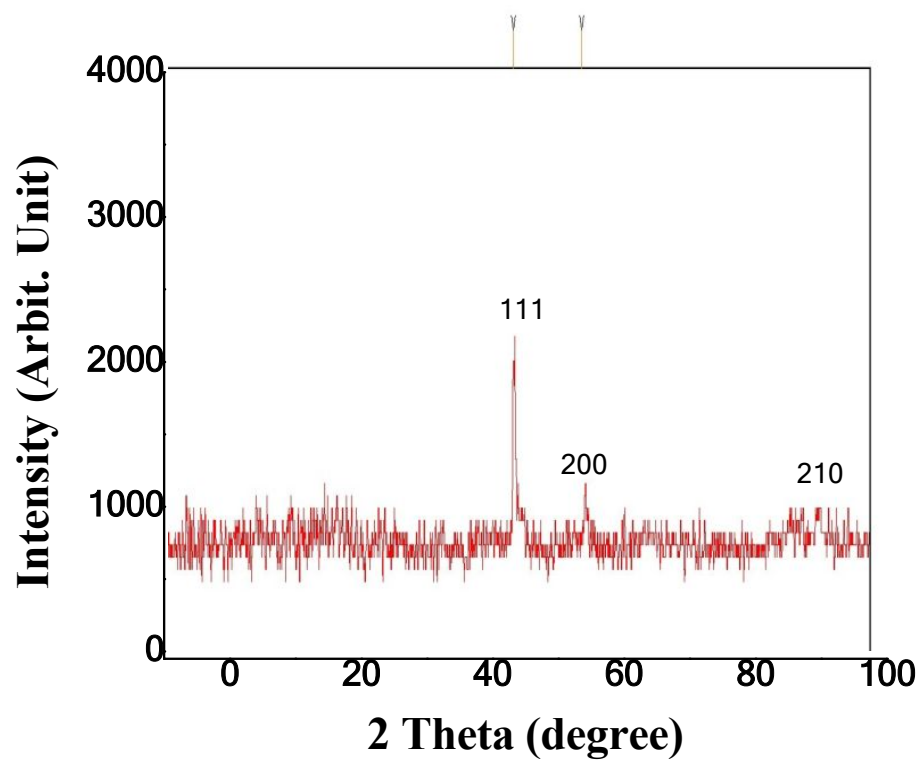

Figure S1. XRD pattern (observed at $42^{\circ}, 58^{\circ}$ and $95^{\circ}$ corresponding to 111,200 and 210) of $\mathrm{Au}-\mathrm{Cu}(3: 1) \mathrm{NPs}$ synthesized by the polyol process from $\mathrm{AuCl}_{3}, \mathrm{CuCl}_{2}$ in the presence of PVP as a capping agent. 


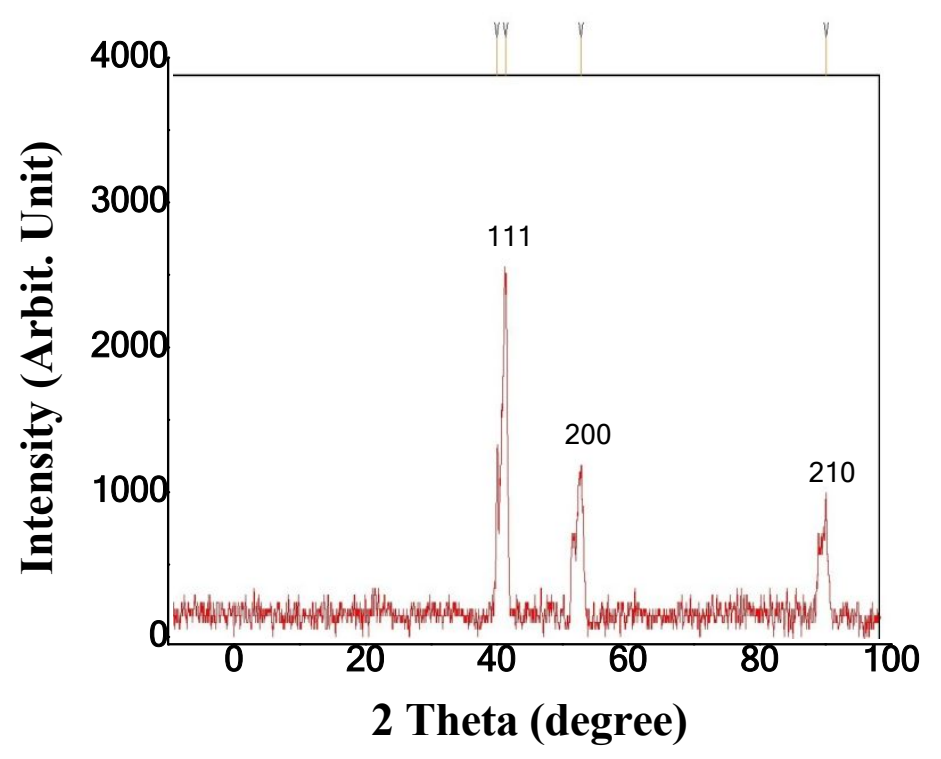

Figure S2. XRD pattern (observed at $40^{\circ}, 55^{\circ}$ and $90^{\circ}$ corresponding to 111,200 and 210) of $\mathrm{Au}-\mathrm{Cu}$ (1:1) alloy NPs synthesized by the polyol process from $\mathrm{AuCl}_{3}$, $\mathrm{CuCl}_{2}$ in the presence of PVP as a capping agent.

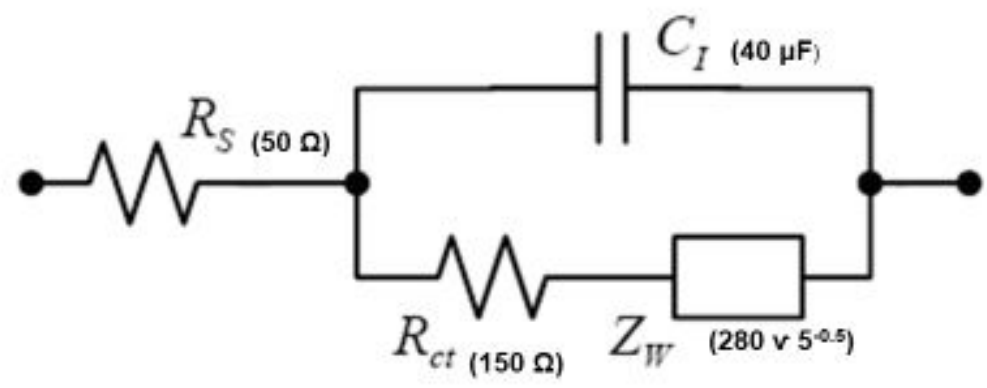

Figure S3: Equivalent Circuit model of EIS for modified $\mathrm{Au}-\mathrm{Cu}$ Electrochemical Sensor 